\title{
ESTUDO DA VIABILIDADE DA UTILIZAÇÃO DA ESCÓRIA DE ACIARIA COMO MATÉRIA PRIMA ALTERNATIVA EM NOVOS PRODUTOS.
}

\author{
Vanessa Cristine Silva \\ Universidade Federal de Minas Gerais \\ vanessacristinesilva@gmail.com
}

Resumo: Este artigo apresenta resultados de uma pesquisa qualitativa cujo objetivo foi estudar a viabilidade do uso da escória de aço como matéria prima alternativa em novos produtos. A partir do levantamento dos tipos de pesquisa utilizados, a bibliografia e documental pertinentes ao tema, buscou-se observar que produtos podem ter como material essa matéria prima, em dada situação específica de mercado. E, como a humanidade vive num complexo processo de mudanças fomentadas pela industrialização, a abordagem deste tema trata da inserção da inovação como instrumento para a transformação, e contribui para incentivar o trabalho com novos materiais. Surge uma nova tendência de que, no futuro, trabalhar matérias primas alternativas procede, quando se pensa no avanço do desenvolvimento tecnológico, em diversos campos de atuação. Os resultados da pesquisa mostram ser viável o uso da escória de aço na concepção do produto e, também, apontam potencialidades de inovação em novas tecnologias de produção.

Palavras-chave: escória de aciaria, matéria prima, inovação.

Abstract: This article presents the results of a qualitative research whose objective was to study the feasibility of using steel slag as raw material alternative in new products. From the types of methodology used - the bibliographical and the documental - pertinent to the theme, research sought to observe which products can have this material as raw material in a particular market situation. As humanity lives in a complex process of changes fomented by industrialization the approach of this theme deals with innovation as an instrument for this transformation and stimulates the work with new materials. There is a new trend which claims that in future to work alternative raw materials will be a reality when one thinks of technological development in various fields of activity. Research results reveal that it is feasible to use steel slag in the product design and also point out potentialities of innovation in new production technologies.

Keywords: steel slag, raw material, innovation. 


\section{INTRODUÇÃO}

[...] não se trata somente de aplicar novas possibilidades tecnológicas ou produtivas específicas, mas de promover novos critérios de qualidade que sejam ao mesmo tempo sustentáveis para o ambiente, socialmente aceitáveis e culturalmente atraentes (MANZINI E VEZZOLI, 2002, p.22).

A indústria siderúrgica é uma atividade intensiva relativa ao uso de energia, água e recursos naturais, e gera, por tonelada, 700 quilos de resíduos sólidos. Portanto, é importante reaproveitar a escória de aço como valor agregado do produto final, estabelecer uma conexão entre a evolução tecnológica e a minimização da degradação ambiental, tendo o design como agente unificador da multidisciplinaridade dentro da realidade mundial (SILVA, 2011).

\subsection{Motivação}

A motivação para esta pesquisa surgiu da realidade vivenciada por esta pesquisadora durante sua observação do processo siderúrgico em uma usina integrada, onde permaneceu por alguns anos, e de sua ansiedade pela investigação do conteúdo de sua monografia intitulada Subsídios para a Inserção do Design como Estratégia para agregar valor ao Resíduo de Siderúrgicas e defendida em 2011. É intenção desta pesquisadora dar continuidade, no mestrado à busca de respostas para novos questionamentos sobre o tema.

\subsection{Objetivo}

O objetivo geral deste estudo é apresentar uma avaliação das possibilidades de reaproveitamento dos tipos de escórias em novos produtos.

\subsection{Metodologia}

Para se desenvolver este estudo, foram utilizadas as pesquisas documental que apresenta regras e diretrizes de um dado contexto de órgãos nacionais e internacionais, e a bibliográfica, esta a mola propulsora desta etapa do trabalho. Garantir a viabilidade da matéria prima escória em novos produtos é uma tarefa complexa que necessita de conhecimentos multidisciplinares. É nesse sentido, que fomenta o exercício da pesquisa multidisciplinar, visto que um número crescente de publicações tem abordado o tema resíduo escória de aciária em diversos campos do conhecimento tais como os de engenharia, agricultura e construção civil. Nesse sentido, durante a revisão bibliográfica, pôde-se perceber que o assunto é muito pouco, ou melhor, quase nada explorado pelo Design. Sob esse prisma, entende-se que a abordagem aqui proposta seria uma contribuição pioneira que se desenvolveria a partir das atividades do design.

\section{REFERENCIAL TEÓRICO}

A revisão da literatura pertinente ao tema tem o aporte de vários autores no que tange à aplicação do uso deste coproduto ${ }^{1}$, como Kiessling $(1978)^{2}$, trabalho no

\footnotetext{
${ }^{1}$ Segundo a ISO 14040, coprodutos são quaisquer dois ou mais produtos provenientes da mesma unidade produtiva ou sistema de produto. Os coprodutos do aço são utilizados como matéria-prima ou fonte de energia na própria atividade produtora ou em atividades/processos de terceiros (ISO 14040, p.9.2006).
} 
qual define Escória de aço como sendo "soluções formadas por óxidos de metais, sulfetos e fluoretos parcialmente ou completamente líquidos, menos densos e insolúveis que o aço líquido nas temperaturas de fabricação".

\subsection{Breve histórico de uso da escória de aciaria}

A geração de escória é tão antiga quanto a produção de ferro, pois data de 2000 AC. No século 350 DC, surge o primeiro relato de seu uso com o filósofo grego Aristóteles, que apontou a utilização da escória como medicamento curativo de feridas.

A história do uso da escória de ferro também remonta ao tempo do império Romano, cerca de 2000 anos atrás, quando da sua aplicação na construção de base das estradas. No apogeu das guerras dos séculos XIV e XV, a Alemanha utilizava escória de ferro para fazer bolas de canhão.

Ainda, na Alemanha, cidade de Troisdorf, em 1862, o engenheiro Eugene Langen pesquisa sobre a escória granulada e demonstra, através de seus ensaios, que a escória moída misturada com cal hidratada poderia ser utilizada na produção de argamassa e que esta mistura superava, até então, a técnica construtiva tendo a cal como componente aglomerante (EURO SLAG, 2014) ${ }^{3}$.

Segundo Rostik, 1999, a Chaparral Steel ${ }^{4}$ (Hoje Gerdau), que fazia parte da Texas Industries Inc., era a maior produtora de cimento do Texas e da Califórnia nos Estados Unidos. Sua aciaria de forno elétrico produzia cerca de dois milhões de toneladas de aço. Em 1995, iniciou-se o programa de meta 100\% de reutilização dos seus resíduos com o nome STAR (Systems and Technology for Advanced Recycling), onde foi priorizada a escória e o pó de aciaria, o consumo e a energia e o resíduo de fragmentadora de automóveis.

Atualmente, a indústria tem buscado processos de beneficiamento da escória, seguindo os requisitos de normas e regulamentos específicos vigentes, para minimizar os reflexos negativos da atividade industrial e planejar formas de utilização racional de sua matéria prima. Hoje, milhões de toneladas de escória são produzidos no mundo e futuro desse número é limitado apenas pela imaginação de seus utilizadores.

\subsection{Seleção de materiais - fator de propriedade}

Segundo Manzini e Vezzoli (2002), o campo dos materiais está em expansão acelerada nos dias atuais. A mudança ocorre rapidamente e a resistência a ela reflete na própria sociedade, em nossos hábitos e nas estruturas fabris por demais repetitivas.

\footnotetext{
2 Kiessling, Roland, Nils Lange - Non-Metallic Inclusions in Steel British Corrosion, Volume 13 Issue 2 (01 January 1978), pp. 55-56. Disponível em DOI: http://dx.doi.org/10.1179/000705978798318891. Acessado em 02/02/2014.

${ }^{3}$ EUROSLAG - The European Association representing metallurgical slag producers and processors, é uma associação europeia de organizações e empresas envolvidas com todos os aspectos da produção e da utilização de produtos de escória siderúrgica. A associação lida com a promoção de escória como um produto, permite a troca de informação e de investigação, bem como facilita a interação com órgãos. Disponível em: htt://www.euroslag.com/. Acessado em 12/04/2014.

${ }^{4}$ A Chaparral Steel Company é a segunda maior produtora de aço estrutural na América do Norte e também uma grande produtora de barras de aço. A empresa opera duas mini mills localizadas em Midlothian, no Texas e Dinwiddie County, na Virgínia. A Chaparral traz não somente produtos de alta qualidade, mas também uma forte organização com excelente capacidade técnica." GERDAU AMERISTEEL. Disponível em: http://www.gerdau.com.br/media-center/noticias. aspx? language=ptBR\&Codigo=a6f07dc6-b5da-46be-9f1f-9183e8ff94db. Acessado em 23/04/2014.
} 
A ocorrência de produção de novos materiais, processos e de novas tecnologias interferem como elementos de mudanças sociais. É diante disso que surge o paradigma do Design que aponta a necessidade de se repensar a atuação profissional e ampliar o foco projetual, diante dos problemas econômicos, sociais e ambientais que se apresentam (MANZINI, 2002).

A escória de aciaria é reconhecida na indústria, por ser uma matéria prima valiosa dadas as suas inerentes e excelentes propriedades, como as químicas, físicas e mineralógicas semelhantes às da rocha natural. Desse modo, a maioria dos campos de aplicação é idêntica aos dessas rochas naturais (EUROSLAG, 2014).

A alta densidade, o valor de abaixo impacto, a resistência à compressão elevada, bem como o bom polimento e a resistência ao congelamento/descongelamento fazem da escória de aço uma ótima matéria prima para a construção de estradas. Também, a sua forma cúbica e a textura de sua superfície áspera proporcionam resistência ao impacto (EUROSLAG, 2014).

A utilização de escórias está totalmente condicionada às características físicas, mecânicas, químicas, ambientais e mineralógicas que estes materiais apresentam. Exibem como fator limitante ao seu uso o problema da expansibilidade. Entretanto, para o reaproveitamento destes resíduos será necessário monitorar este fenômeno, através de pesquisas e regulamentações, buscando, dessa maneira, sua adequação e aplicação, de acordo com suas características e propriedades.

\subsection{O estado da arte do uso da escória}

Para consolidar a proposta desta pesquisa, nesta subseção, é apresentado o resultado das possibilidades de aplicação e transformação do resíduo de escória de aciaria em novos produtos. Entretanto, deve-se levar em consideração que, dependendo do processo de fabricação do aço, obtêm-se escórias com características muito diferenciadas umas das outras. De forma que se faz necessário o estudo de cada escória específica, antes de seu uso.

Pode-se dizer que esta pesquisa é considerada uma atividade sistemática, um questionamento entre o diálogo crítico e a realidade que nunca de esgota.

Foram pesquisados os seguintes tipos de escória:

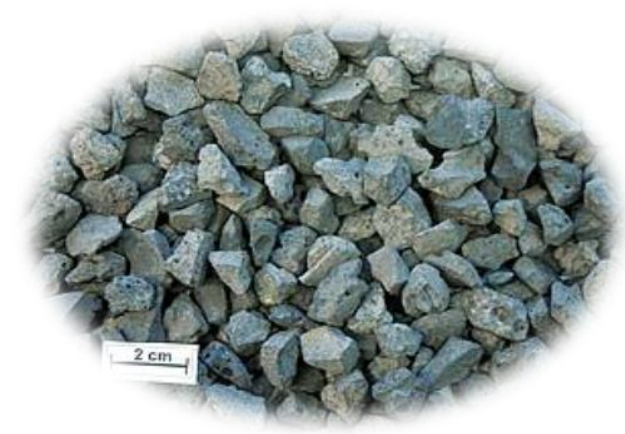

Figura 1: Escória BOF, EUROSLAG 5 .

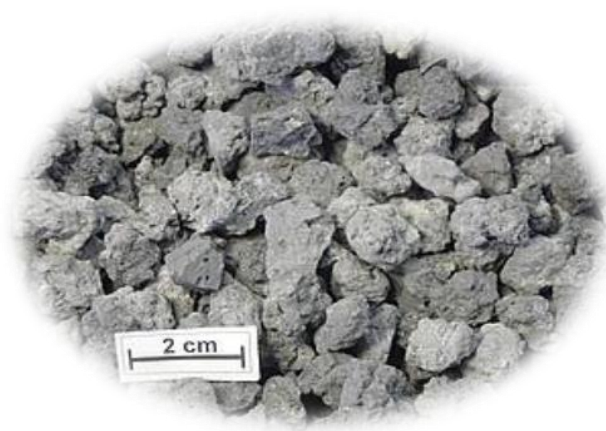

Figura 2: Escória FEA, EUROSLAG.

\footnotetext{
${ }^{5}$ Disponível em: http://www.euroslag.com/products/properties/. Acesso em 14/04/2104.
} 


\subsubsection{Escória de aciaria LD ou BOF (basic oxygen furnace) refino oxidante}

Nos processos industriais de transformação do ferro gusa em aço líquido, as escórias de aciaria do tipo LD referem-se ao método de produção do aço. A sigla LD refere-se ao fato do aço ser produzido no conversor de oxigênio tipo LD, sigla para Linz e Donawitz, cidades da Áustria, onde este processo foi criado (AISI, 2014) ${ }^{6}$.

\subsubsection{Uso da Matéria prima escória na fabricação de vitrocerâmica.}

A Versatilidade e a Inovação de um produto surgem para agregar um novo valor à matéria prima escória, através de uma pesquisa desenvolvida com o departamento de engenharia da universidade de São Carlos, em conjunto com a Usiminas. Os experimentos realizados neste trabalho comprovam o uso da escória de aciaria para o desenvolvimento de vidros e da vitrocerâmica, considerando suas propriedades superiores às cerâmicas convencionais. Na sua composição de $60 \%$ de escória, $35 \%$ de areia e $5 \%$ de $\mathrm{Na} 20$ (após fusão a 1350 ㄷ) , é possível produzir placas de vidros e vitrocerâmicas para serem utilizadas como revestimento na construção civil. Segundo Scudeller, líder do referido projeto, as vitrocerâmicas produzidas com escória de aciaria são ideais para revestimentos arquitetônicos, competindo com os tradicionais produtos considerados top de linha, tais como: grés-porcelanato, pastilhas e pisos autossustentáveis, além de suas características mais atrativas que as das cerâmicas convencionais, como uma maior resistência mecânica (não quebram facilmente) e à abrasão (suportam tráfego intenso de pessoas e de máquinas pesadas) $\left(\right.$ IABR, 2014) ${ }^{7}$.

\subsubsection{Uso como matéria prima alternativa para a fabricação de lã mineral.}

A indústria de lã mineral está, cada vez mais, absorvendo matéria prima alternativa em seus produtos. Atualmente, em sua composição, utiliza rocha vulcânica, (entre elas o basalto e o calcário), juntamente com a escória de aciaria na proporção de $97 \%$. Durante a fabricação da lã, a rocha e a escória siderúrgica (aciaria e alto forno) são fundidas em forno aquecido a $1500^{\circ} \mathrm{C}$, que são transformados em filamentos aglutinantes, tais como amido e cal, que permitem a fabricação de produtos leves e flexíveis, e até muito rígidos, dependendo do grau de compactação (FRIEDMAN, 2013) 8. A Baosteel, uma das maiores siderúrgicas da China, é classificada entre as 100 maiores empresas verdes, em função da reciclagem de seus coprodutos. Em 2011, essa usina criou a primeira empresa mineral na China, utilizando como matéria prima a escória de aciaria para a produção do material de isolamento térmico à prova de fogo (BAOSTEEL, 2014) ${ }^{9}$.

\footnotetext{
${ }^{6}$ AISI - American Iron and Steel Institute. Steel Works The On Line Resource For Steek. Massachusetts, Washington. 2014. Disponivel em: http://www.stell.org/Making Steel/How Its Made/Processes/Processes Info/The Basic Oxygen Steelmaking Process.aspx. Acesso em 04/04/2014.

${ }^{7}$ IABR - Instituto Aço Brasil. Disponível em: http://www.ccabrasil.org.br/noticias.asp?id-16. Acessado em 30/03/2014.

${ }^{8}$ Dan Joe Friedman, Rock Wool, Mineral Wool, \& Slag Wool Building Insulation Identification, Washington.2014. Disponível em: http://inspectapedia.com/interiors/Rock_Wool_Insulation.htm. Acessado em 06/04/2014.

${ }^{9}$ Baosteel. Disponível em: http://www.baosteel.com/group_en/contents/2863/39896.html. Acessado em 06/04/2014.
} 


\subsubsection{Utilização em materiais cerâmicos}

Diversos trabalhos abordam a incorporação de escória de aciaria em materiais cerâmicos. Para Lobato (apud FREITAS et al.2012), a utilização de escórias nas massas cerâmicas se deve ao fato de esse possuir a função de fundente, conferindo um aumento da resistência dos materiais cerâmicos. Foi observado que, ao incorporar $30 \%$ de escória de aciaria, $50 \%$ de filito e $20 \%$ de argila, o material cerâmico final apresentou boa resistência mecânica.

Nas análises de Bennedth et al. (2012) ${ }^{10}$, foram processadas possibilidades da matéria prima em revestimento cerâmico, utilizando argila mineral caulinite e escória de aciaria na gama de $0-100 \%$ em peso. Os resultados obtidos mostraram que, nas amostras contendo de 20 a 60 \% em peso escória de aciaria têm boas propriedades para revestimento cerâmico. Os testes mecânicos confirmaram a alta qualidade deste produto e seu uso para pisos cerâmicos.

\subsubsection{Escória de aciaria FEA do refino oxidante}

A escória de aciaria de forno elétrico a arco (FEA) é, hoje, a maneira mais comum para a reciclagem de aço a partir da sucata. Segundo a norma JIS A 5015/1992, a escória de forno elétrico pode ser: oxidada ou reduzida, de acordo com a temperatura do forno durante o processo de refino. Para a escória oxidada, a matéria prima (sucata metálica) é fundida por meio de arco. O oxigênio é soprado no aço líquido, oxidando as impurezas presentes, cujos óxidos combinam com a cal adicionada como fundente, formando, assim, a escória. Parte do ferro oxidado penetra na escória, o que a transforma num material mais pesado e mais duro que o macadame natural comum. No caso da escória reduzida, após o vazamento de escória oxidada, adiciona-se a cal ao aço líquido, a qual se combina com as impurezas como os óxidos, formando, assim, a escória reduzida (JIS A 5015, 1992).

\subsubsection{Uso na fabricação de tijolo de solo-cimento}

No ano de 2004, em Taiwan, sudoeste da China, foi realizado o experimento do uso combinado de argila com escória siderúrgica para a produção de tijolos. As propriedades avaliadas no produto foram: absorção de água, resistência à compressão e alterações dimensionais pela secagem e pela temperatura de queima. Foram feitas várias formulações utilizando de 0 a 30\% de agregado de escória na mistura com argila. Os resultados obtidos nos tijolos, no ensaio de compressão, indicam que eles satisfazem aos critérios das respectivas normas do país (LOBATO, 2004).

Na Siderúrgica ArcelorMittal no Brasil, em 2010, foi aprovada a produção industrial, em série, dos bloquetes ecológicos sextavados para pavimentação urbana, pela Superintendência Regional de meio ambiente e desenvolvimento sustentável (Supram), da Zona da Mata. Esse produto é produzido com a matéria prima escória de forno elétrico e terra de Sherdder (gerada do beneficiamento de sucata metálica). Conforme exposto no relatório de sustentabilidade da ArcelorMittal, em Juiz de Fora MG, este produto oferece muitas vantagens ao uso: o custo é $25 \%$ menor do que o dos bloquetes convencionais, evita o consumo de recursos naturais não renováveis (areia e

\footnotetext{
${ }^{10}$ Benedith C. Chukwudi, Patrick O. Ademusuru, Boniface A. Okorie. Characterization of Sintered Ceramic Tiles Produced from Steel Slag. Journal of Minerals and Materials Characterization and Engineering, p. 863-868. 2012.
} 
brita) e tem maior permeabilidade, flexibilidade, resistência à compressão e característica antiderrapante (RELATÓRIO DE SUSTENTABILIDADE, ARCELORMITTAL 2013).

Nenhum outro uso da escória de aciaria foi detectado.

\subsubsection{Uso no isolamento de radiações.}

Em situação em que haja blindagens de radiações, por exemplo, em hospitais, o agregado siderúrgico A.S.I.C. satisfaz às exigências de barreiras de proteção nas salas radioativas, substituindo o barite ${ }^{11}$, de uso comum nas paredes. (PACHECO, 2012).

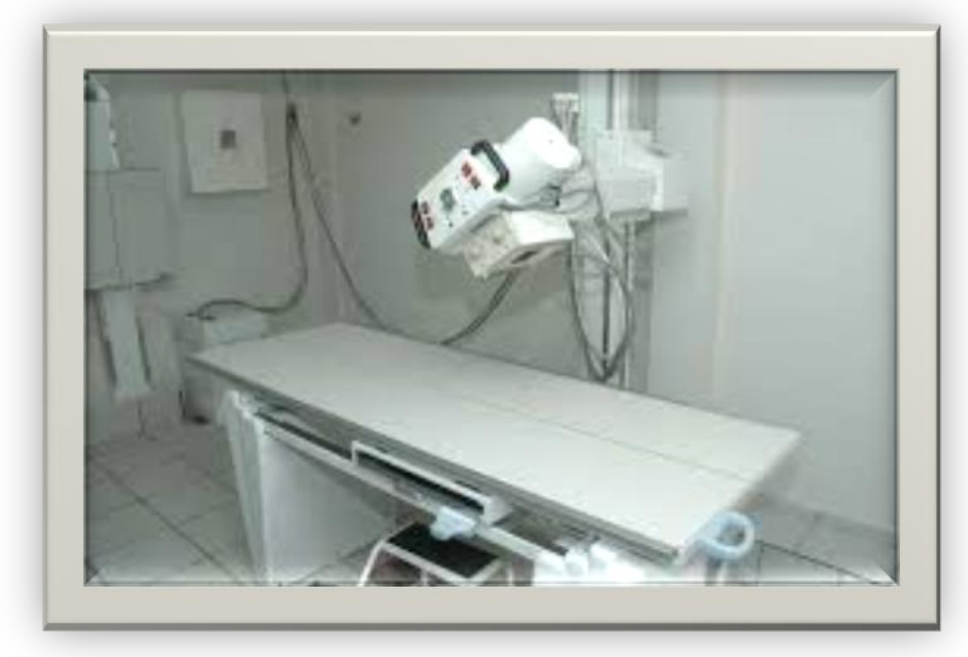

Figura 3: Exemplo de parede em sala de raios-X, PACHECO, 2012.

\subsubsection{Uso como barreira na dissipação de energia das ondas em orlas marítimas.}

Segundo a argumentação de Tanube et al. (2007), com o agregado de escória de aciaria é possível conceber blocos para serem utilizados para dissipar energia das ondas marítimas, obtendo a forma de barreira única contra as marés. Antes, eram utilizados blocos de pedra natural que não possuem formas padronizadas, não permitindo, assim, um melhor arranjo entre elas, e fazendo com que, num curto espaço de tempo, a força do mar vença estas barreiras artificiais. Diante deste fato, a execução da barreira com o agregado siderúrgico não só obtêm um elemento de peso, como também de maior resistência ao impacto.

\subsubsection{Uso como recifes artificiais tetrápodes}

Takahashi, T. e Yabuta K. (2002), do Centro de Tecnologia da NKK, Siderúrgica japonesa, introduziram inovação na sua pesquisa para a aplicação da escória de aciaria. Esta nova tecnologia consiste na confecção de blocos de escória ou recifes artificiais marítimos, com o objetivo de promover a biodiversidade e o desenvolvimento sustentável para o território japonês. O experimento realizado

\footnotetext{
${ }^{11}$ Barita (BaSO4) ou sulfato de bário, segundo (Klein e Dutrow, 2007) é bem conhecida por sua grande variedade de cores e formas cristalinas tabulares. Sua dureza varia de 3 a 3,5 Mohs. O nome barite tem origem do grego "barus" que significa pesado. Seus principais produtores estão na China (3.600 mil ton), Estados Unidos (670 mil ton) e no Marrocos (250 mil ton.).
} 
permitiu investigar o efeito de blocos de escória no cultivo da biodiversidade marinha. Em novembro de 1997, foram introduzidos blocos de escória de aciaria no fundo do mar da costa da cidade de Hiroshima e, em 1998, pode-se identificar o crescimento de plantas marinhas e de peixes ao redor dos blocos. Percebeu-se que a superfície dos blocos feita com escória é porosa e composta por $\mathrm{CaCO}_{3}$, a mesma substância que compõe os recifes. Este fato promove a ampliação da quantidade de espécies de plantas e animais marinhos nos blocos e em suas proximidades. As cavidades presentes nos blocos, devido à porosidade e ao $\mathrm{pH}$ do material que não agride ao meio ambiente são consideradas uma das causas do desenvolvimento a que se chegou. 0 crescimento de plantas marinhas em blocos de escória foi comparado ao do bloco de granito e ao de concreto com as mesmas dimensões e no mesmo local. Os blocos de escória apresentaram maior crescimento de plantas marinhas em sua superfície.

No Brasil a ArcelorMittal Tubarão, no Estado do Espírito Santo, desenvolve uma parceria com o Instituto Ecos para a inserção de recifes em forma de pirâmides. 0 projeto consta com a participação da comunidade local, e seu intuito é o de gerar ações de educação ambiental e oportunidade de trabalho para os habitantes do Município de Serra, na costa capixaba (ARCELORMITTAL, 2014).

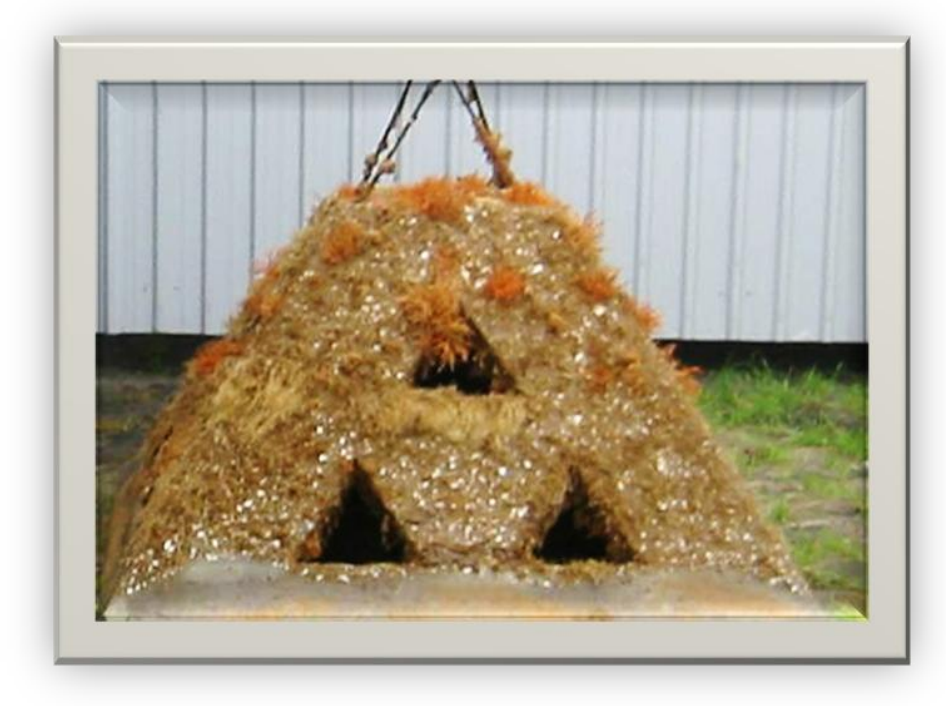

Figura 4: Recife artificial Estado do Espírito Santo, ARCELORMITTAL, 2014.

\subsubsection{Perfis New Jersey ${ }^{12}$}

Em sua pesquisa de mestrado, Pacheco (2012) comprova a indicação do A.S.I.C. ao tipo de produto, atribuindo sua boa característica mecânica ao impacto ao uso de barreiras de segurança. Este tipo de produto é usado para isolar os veículos no fluxo de tráfego. $O$ objetivo deste produto consiste em minimizar o impacto do veículo, através da angulação na base do perfil (PACHECO, 2012).

\footnotetext{
${ }^{12}$ “Esse perfil é definido em várias normas e documentos técnicos como, por exemplo, a Norma Francesa NFP 98-430, a "Circulaire № 88-49 Mai 1988" do Ministère de L'Équipement, du logement, de L’Aménagement du Territorie et dês Transports", da França, ou a publicação "Barriéres de Sécurité pour la Retenue dês Véhicules Légers, Collection du Guide Technique GC", S.E.T.R.A. 2001. InIR, I.P. Instituto de Infra-Estruturas Rodoviárias - Disposições Normativas: BARREIRAS NEW JERSEY COM VALETA ADJACENTE - CONDIÇÕES E PARÂMETROS DE SEGURANÇA. 5p.
} 


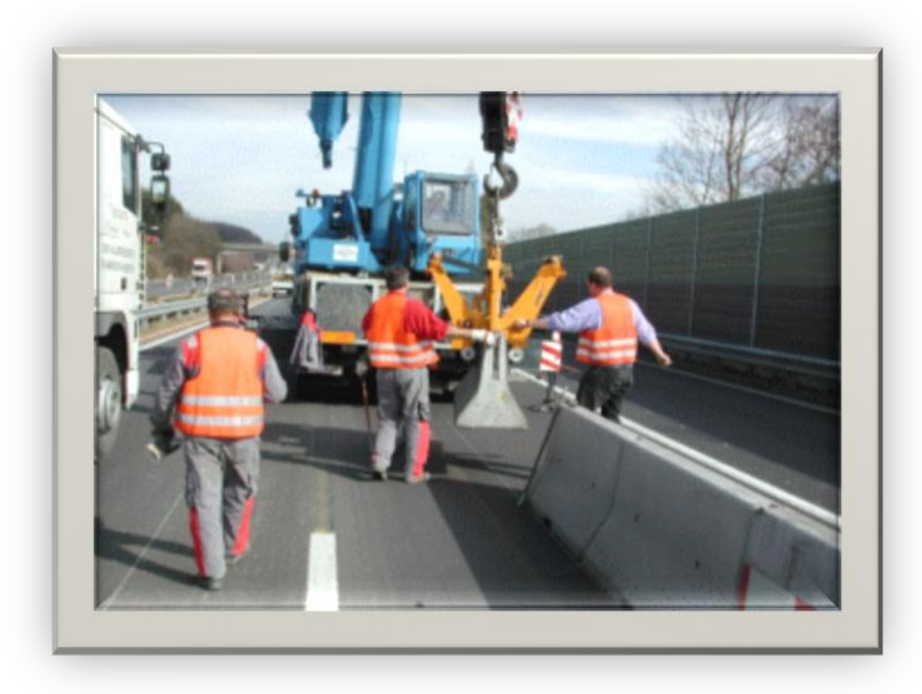

Figura 5: Perfil New Jersey, HARSO, 2014.

\subsubsection{Uso de escória na agricultura}

O Japão é pioneiro na utilização da escória de aciaria como fertilizante para a agricultura. O próprio instrumento de legislação do país regulamenta o uso da escória e determina que outros produtos derivados desta matéria prima sejam certificados. Os benefícios do fertilizante produzido pela escória à agricultura é potencialmente composto de minerais que controlam a acidez do solo, auxilia no controle de pragas e melhora a qualidade do produto.

Também, na China, a siderúrgica Taiyuan Iron \& Steel (TISCO) fabricou um produto de escória de aciaria rico em silicato de cálcio, que tem apresentado resultados positivos para a agricultura. Tal tecnologia é fator relevante para as regiões chinesas, visto que dados estatísticos revelam que 50 milhões de hectares são insuficientes em silício no seu solo, e este sofre com os efeitos da chuva ácida nas explorações de mineração e carvão (HARSCO, 2014).

\subsubsection{Uso na produção de biocombustível}

Kashiwaya et al. (2007) comprovaram a possibilidade da escória de aciaria LD, como catalisador de produção de biodiesel. No estudo apresentado ao ISIJ Internacional, intitulado Catalytic Effect of Slags on the Formation of Biodiesel Fuel, o experimento do aquecimento térmico da escória a $1000^{\circ} \mathrm{C}$, num período de 24 horas, resultou no potencial de elevação de teor do éster metílico em $56 \%$ de ácido graxo, que consiste no principal componente do biodiesel.

\subsubsection{Uso na absorção de impurezas em águas residuárias.}

Ramakrishna et al (1997) estudaram em escala de laboratório, a aplicação da escória de aciaria para remoção de coloração provocada por tintas em águas residuárias. Justifica-se a utilização da escória de aciaria como substituta do carvão ativado no processo de absorção das impurezas iônicas pelo fato de suas partículas possuírem alta porosidade, grande área superficial e elevada variedade de tamanhos. 


\section{CONCLUSÃO}

Estudos realizados por diversas entidades e universidades nacionais e internacionais, assim como o histórico da utilização da escória, não indicam que ocorrem impactos ambientais significativos, ou seja, que se alteram as condições ambientais locais onde se aplicou a escória de aciaria. A participação da Europa e de alguns países asiáticos (Japão, China, Coreia do Sul e Taiwan) na vanguarda dos estudos de incorporação da tecnologia do reaproveitamento do resíduo tem gerado um crescimento considerável no número de instituições de pesquisa sobre o tema. A escassez e o elevado custo das matérias primas são os fatores que impulsionam a reciclagem desses coprodutos.

Mathur, Soni e Murty (2001) informaram à comunidade científica que a Índia possui uma larga rede de usinas siderúrgicas, gerando uma grande quantidade de escória, além de outros rejeitos. Nesse contexto, a problemática reside na falta de normas técnicas para o reaproveitamento desses resíduos e, consequentemente, há a formação de grandes pilhas de escória que ocupam boa parte do território indiano. Ainda, segundo a argumentação destes autores, este cenário é comum em diversos países, incluindo o Brasil.

Lamentavelmente, neste contexto mundial, a participação do Brasil é ainda incipiente no que tange à quantidade de escória produzida pela indústria.

O exposto nesta pesquisa apontou para a necessidade de uma integração, cada vez maior, entre os pesquisadores de todos os continentes, já que várias pesquisas vêm sendo desenvolvidas, simultaneamente, em todo o mundo, abordando problemas comuns a muitos países.

Nesse sentido, deve-se colocar em evidência a importância do papel decisivo da esfera governamental na reutilização dos resíduos, visto que é através de imposições dos instrumentos de normalização e da fiscalização rígida que se impede a poluição do meio ambiente, responsabilizando os agentes poluidores pela reciclagem e reutilização de seus resíduos, sendo esta uma das causas que impulsionam o desenvolvimento de pesquisas que objetivam soluções alternativas para a problemática das escórias.

Este artigo visou a levantar uma discussão sobre outras possibilidades de obtenção de produtos por meio da matéria prima escória de aço. Objetivou, também, identificar a destinação da escória de aciaria, no que tange à degradação ambiental.

Cabe, ainda, ressaltar que esta pesquisa fomenta o exercício da reflexão sobre a complexidade de se fazer com que este resíduo seja produzido de forma sustentável, e que seu produto final tenha seu valor agregado no mercado.

Agradecemos ao Programa de Pós-Graduação do Mestrado do Ambiente Construído e Patrimônio Sustentável da Escola de Arquitetura da UFMG.

\section{REFERÊNCIAS}

Normas técnicas:

INTERNATIONAL ORGANIZATION FOR STANDARDIZATION - ISO. ISO 14040. Environmental management - Life cycle assessment - Principles and framework. Geneva. 2006. 20p. 
JAPAN INDUSTRIAL STANDARDS.

JIS A 5015. Escória Siderúrgica para Construção de Estradas. 1992. Iron and

steel slag for Road construction (FOREIGN STANDARD).

Referências de Livro:

a) com um autor

MANZINI, Ezio; VEZZOLI, Carlo. O desenvolvimento de produtos sustentáveis: os requisitos ambientais dos produtos industriais. Tradução de Astrid de Carvalho. São Paulo: Editora da Universidade de São Paulo. EDUSP. 2002.

RIZZO. E. M. S. Introdução aos Processos Siderúrgicos. São Paulo. Associação Brasileira de Metalurgia e materiais. 150p. 2005.

b) com mais de três autores

Instituto de Infraestruturas Rodoviárias - Disposições Normativas: BARREIRAS NEW JERSEY COM VALETA ADJACENTE - CONDIÇÕES E PARÂMETROS DE SEGURANÇA. 5p.

Dissertações, teses, monografias e trabalhos acadêmicos:

a) Dissertação/Tese

LOBATO, N. C. C. Gerenciamento de Resíduos Sólidos da Indústria Siderúrgica. 2014. 156 p. Dissertação de Mestrado. Programa de Pós-graduação em Engenharia Metalúrgica, Materiais e de Minas. Universidade Federal de Minas Gerais, Belo Horizonte, 2014.

PACHECO, ALEXANDRE EMANUEL LEITÃO. Estudo da viabilidade da utilização de escórias de aciaria (ASIC) em Betão denso. Dissertação de Mestrado em Engenharia Civil. Universidade do Porto. Portugal. 2012.

SILVA, Vanessa Cristine. Subsídios para a Inserção do Design como Estratégica para Agregar Valor ao Resíduo de Siderúrgicas: Caso do polo industrial do Alto Paraopeba, Vale do Aço e Zona da Mata, MG. 2011. Monografia (Especialização) - Universidade Federal de Minas Gerais.

Eventos:

KASHIWAYA, Yoshiaki; TOISHI, Keigo; KANEKI, Yuichi; YAMAKOSHI, Yukiyasu. Catalytic Effect of Slags on the Formation of Biodiesel Fuel. ISIJ International, v. 47, n. 12, p. 1829-1831. 2007.

MATHUR. S.; SONI, S. K.; MURTY, A. Utilization of industrial wastes im low-volume roads. In: Transportation Research Record 1652. 2001. p. 246-256.

RAMAKRISHNA, K. R.; VIRARAGHAVAN, T. Use of slag for dye removal. Waste Management. Vol. 17. №. 8. 1997. pp. $483-488$.

ROSTIK, L. F. EAF Steel Company on the by-product synergy environment In: REWAS 99 p. 1593-1603. San Sebastian, Spain. 5-7 September 1999. 
Entrevista, palestra e discurso:

Bennedth C. Chukwudi, Patrick O. Ademusuru, Boniface A. Okorie. Characterization of Sintered Ceramic Tiles Produced from Steel Slag. Journal of Minerals and Materials Characterization and Engineering, 863-868. 2012.

Takahashi, T. \& Yabuta K. New Applications for Iron and Steelmaking Slag NKK Technical Review No 87, 2002.and Engineering, 863-868. 2012.

TANABE, H.; NAKADA, M. Steelmaking Technologies Contributing to Steel Industries. NKK Technical Review ${ }^{\circ}$ 88. P. 18 - 27. 2003.

Meio Eletrônico:

a) Internet

American Iron and Steel Institute. Steel Works The On Line Resource For Steek. Massachusetts, Washington. 2014. Disponível em: <http://www.stell.org/Making Steel/How Its Made/Processes/Processes Info/The Basic Oxygen Steelmaking Process.aspx>. Acesso em 04 de abril de 2014.

Baosteel. Disponível em:

<http://www.baosteel.com/group_en/contents/2863/39896.html>. Acesso em 06 de abril de 2014.

Dan Joe Friedman, Rock Wool, Mineral Wool, \& Slag Wool Building Insulation Identification, Washington.2014. Disponível em: <http://inspectapedia.com/interiors/Rock_Wool_Insulation.htm>. Acesso em 06 de abril de 2014.

GERDAU AMERISTEEL. Disponível em: <http://www.gerdau.com.br/mediacenter/noticias.aspx?language=pt-BR\&Codigo=a6f07dc6-b5da-46be-9f1f 9183e8ff94db>. Acesso em 23 de abril 2014.

HARSCO. Disponível em: <http://www.harsco.com/>. Acesso em 09 de jan. 2014.

Instituto Aço Brasil. Disponível em: <http://www.ccabrasil.org.br/noticias.asp?id-16>. Acesso em 30 de março de 2014.

Kiessling, Roland, Nils Lange - Non-Metallic Inclusions in Steel British Corrosion, Volume 13 Issue 2 (01 January 1978), p. 55-56. Disponível em DOI: <http://dx.doi.org/10.1179/000705978798318891>. Acesso em 02 de fev. 2014.

RELATORIO DE SUSTENTABILIDADE ARCELORMITTAL, 2013. Disponível em: $<$ http://www.arcelor.com.br/pdf/responsabilidade-corporativa/relatoriosustentabilidade/relatorio-sustentabilidade-IABR.pdf>. Acesso em 20 de abril 2014.

The European Association representing metallurgical slag producers and processors. Disponível em: <htt://www.euroslag.com/>. Acesso em 12 de abril 2014. 